\title{
Opacity and Exclusivity in Electronic Securities Trading: The Case of Dark Pools
}

\section{A Comparison of Liquidnet with Electronic Exchanges}

\author{
Bartholomäus Ende', Jan Muntermann ${ }^{2}$ \\ ${ }^{1}$ E-Finance Lab, House of Finance, Grüneburgplatz 1, 60323 Frankfurt \\ ${ }^{2}$ House of Finance, Goethe University Frankefurt, \\ Grüneburghlatz 1, 60323 Frankefurt
}

\section{Introduction}

This paper draws attention to a particular type of alternative trading systems called dark pool which has become popular recently. One particularity of dark pools is their special market model, which is based on opacity and exclusive access.

Whereas in Europe dark pools are still establishing themselves, already more than 40 of them operate in the US and cover approximately $9 \%$ of the overall trading volume (The Economist 2009, Spicer 2009, p. 1). Thus, even the US Securities and Exchange Commission investigates whether the segmentation of order flow caused by dark pools in combination with their low transparency negatively affects price discovery (Spicer 2009, p. 1). From a theoretical perspective, this question has been addressed by Hendershott and Mendelson (2000), who analyzed the impact of crossing networks on dealer markets. As institutional investors claim the need of dark pools for their large order volumes this paper draws attention onto another research question: what is the business value which dark pools create for their members.

Therefore, we have analyzed the prominent example of Liquidnet Europe - a major agency broker dark pool which launched in 2001. In general, Liquidnet represents an IT-based extension of traditional upstairs markets for large orders (block orders) which aims at satisfying its members' trading requirements: trading block orders with no negative price movement (market impact). Compared to the traditional broker intermediated handling of large block volumes, which is based on bilateral negotiations and indications of interests (IOI), it enhances anonymity and trading control. As Liquidnet maintains a closed user group of buy-side institutions, large in AuM, the competitive advantage of negligible market impact costs should provide sustainable benefits when trading large volumes. Market impact is 
one of the major transaction cost components in securities trading, especially when analyzing large order volumes (Madhavan 2000, p. 220). The important role of transaction costs in this field is supported empirically, too: for example, Bikker et al. (2007, p. 976) report that trades of a large pension funds causes average market impact costs of $20 \mathrm{bps}$ for buy and even $30 \mathrm{bps}$ for large sell orders. To elaborate the potential business value provided by dark pools, we have analyzed Liquidnet trades and benchmarked their execution prices with limits available at the instruments' primary markets.

The reminder of this paper is structured as follows: The next section outlines the differences between traditional European exchanges and dark pools. Then, we present our study setup including dataset description followed by the results of the empirical analyses. Finally, we provide a conclusion and further issues being subject to further research.

\section{Electronic Securities Trading}

Exchanges are places where different trade interests are aggregated. They date back to the middle ages and have not undergone significant changes until the late 1980s. At this time, the London Stock exchange introduced SEAQ, a system where market makers display their quotes electronically. The success of this system represents the first significant step of an IT-driven transformation from traditional floorbased towards fully automated electronic order-driven systems (Schwartz and Francioni 2004, p. 299). Nowadays, all European major exchanges exhibit fully electronic trading platforms featuring a central limit order book (CLOB): Deutsche Börse utilizes Xetra, the London Stock Exchange SETS and the Euronext markets employ NSC. This electronification allows investors to trade without being physically present at an exchanges' floor. Further, investors might benefit from trading at multiple trading venues simultaneously (Foucault and Menkveld 2002, p. 151).

The relevance of this opportunity is enforced by the introduction of the Market in Financial Directive (MiFID) in November 2007. MiFID has ended the concentration of stock trading on national stock exchanges in various European states. This fostered competition among trading venues as it allows off-exchange trading at so-called Multilateral Trading Facilities. Accordingly, the number of dark pools, which have originally become popular in the USA, is steadily increasing in Europe (The Economist 2009).

\subsection{Central Limit Order Books - the Principle of nowadays Exchanges}

At European exchanges market participants pass their buy (sell) orders to an electronic CLOB that attempts to match them with corresponding ones which reside already at the ask (bid) side of the book. In general, orders can be distinguished between such with an assigned reservation price (limit) and unpriced ones: The 
former are called limit orders and are executed in the case of a buy not for a higher and in case of a sell not for a lower price than their limit. In contrast, market orders will be executed immediately against the available volume at the best possible prices. Thereby, when the volume at currently best limit is completely executed, the remaining order will be matched against the next best limit resulting in market impact costs. Orders that cannot be executed completely and do not feature special deletion flags will be stored in the CLOB until their expiry date. This is done with price/time priority: E.g. on either side the best available limit prices are on top of the book. All orders with the same limit descend according to arrival time. The difference between best bid and best ask limit is called bid-ask spread. The interval between those two limits of the first level is called inside market, depicted in Figure 1. The midpoint represents the market participants' assessment of the instrument's fair value.

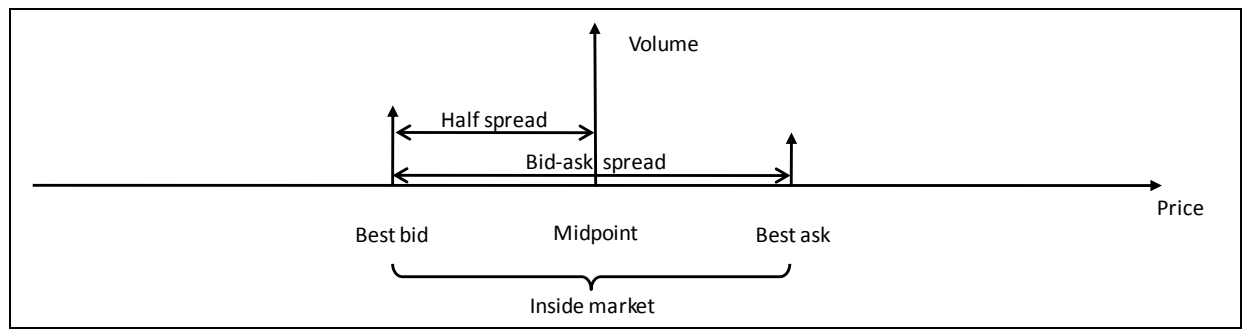

Figure 1: Limit price relationships within a central limit order book (CLOB)

The order matching procedure mentioned above belongs to continuous trading as trades can occur at each point in time when liquidity is present within the CLOB. Beside this mechanism, the exchanges considered in this paper also employ call auctions to derive valid reference prices at the start/center/end of the trading day. Here, trade intentions (liquidity) are pooled together to determine one single price at which all applicable orders will be executed. Continuous trading can also be interrupted by orders leading to price movements that exceed pre-defined ranges. For the considered exchanges, this triggers volatility interruptions (unscheduled auction) for a minimum of two minutes, which might lead to a violation of price continuity.

\subsection{The Challenge of Institutional Order Flow}

Nowadays, trading activity is predominantly triggered by institutional investors (Schwartz and Francioni 2004, p. 114). In contrast to retail order flow, they generate large trade volumes. Although such volumes are instrumental to determine a consensus value for an instument, institutional investors are reluctant to expose their orders for price discovery. The reason is that in markets implementing an open order book approach, this immediately results in market impact. This negative price movement will be triggered by the execution of a large marketable order, 
which sweeps the CLOB. Also, a large unexecuted limit order highlights an imbalance of supply and demand to other market participants. This issue makes block trades vulnerable to front running. Here, other market participants who become aware of the large order volume try to trade ahead of it. In doing so, they aim at taking advantage of the market impact induced by the original large volume. Simultaneously, this practice further influences prices negatively (Harris 2003, p. 245). Thus, anonymity is of major importance for institutional investors.

Several studies like Chan and Lakonishok (1995) or Schwartz and Steil (2002) outline that the execution of institutional orders typically requires more than one trading day. This phenomenon is attributed to the mechanisms utilized to bring these orders to open order books. In general, they are based on aggregating liquidity over time. Usually, brokers slice institutional orders and time their submission. In nowadays markets, also IT-based alternatives exist: One such solution are iceberg or hidden orders directly integrated to electronic trading platforms like Xetra or NSC. This special extension of limit orders features a peak volume. While the main volume remains invisible, the peek is added to the order book during continuous trading. After it is completely executed and undisclosed volume still prevails a new peak is entered. In auctions, iceberg orders participate with their complete volume. Another and more elaborate method is Algorithmic Trading as it allows dynamic adjustments of limit prices and volumes for each individual suborder. For the case of cross-listed securities, Smart Order Routing technology might apply as well. This approach provides an automated search for fragmented liquidity across multiple venues. Further, it is capable of routing orders to the most appropriate venue combination. The importance of the last two solutions is highlighted by studies like Prix et al. (2007) or Gsell and Gomber (2009) who show the increasing market share of automated trading.

In general, the above-mentioned approaches result in an adaptation of institutional orders to the requirements of the CLOB instead of providing a market mechanism for large trading volumes (Schwartz and Francioni 2004, p. 117). For this purpose, there exist alternative trading systems being specialized in trading block orders. One such alternative are dark pools. These are non-transparent liquidity pools in which investors can place orders without revealing themselves or their order details (i.e. instrument and volume). Usually, dark pools can be accessed by large investment firms or hedge funds only, i.e. only selected participants of the dark pool can benefit of the liquidity that it offers. Thus, the business model of dark pools therefore significantly differs from exchanges with a CLOB since it is based on exclusivity and opacity.

\subsection{Dark Pool Trading: The Case of Liquidnet}

Liquidnet is one of the largest agency broker dark pools with currently more than 500 most large buy side institutions. To satisfy the needs of institutional investors, Liquidnet employs a two-step approach (Liquidnet 2001): First, based on the trade 
intentions of its members, a decentralized search within its peer-to-peer network is performed. Thereby, all kind of information concerning the true intentions and involved companies are kept completely confidential. After the identification of suitable trade interests, the system remains passive, i.e. no executions are triggered. Instead, while still keeping the involved institutions' identities private, Liquidnet informs them about the existence of potential trade opportunities. In doing so, the institutions are enabled to open anonym bilateral negotiations in a second step. There, they can negotiate the actual trade volume and price to be traded via $\mathrm{Li}$ quidnet.

To minimize any leakage of information, Liquidnet pursues multiple strategies: First, it employs barriers to entry to form a closed and homogenous user group. Therefore, only large buy-side institutions with more than $500 \mathrm{~m} \$$ assets under management are permitted (Schwartz 2009). As of $31^{\text {th }}$ July 2008 these were 535 member firms worldwide with on average above 19 bn€ AuM (Liquidnet 2009). In addition, the members are supposed to utilize an order management system (OMS) for which an adapter to Liquidnet's peer-to-peer network is provided. This allows a straight-through processing for the first step. As OMSs are said to exhibit only true trade intentions, this is simultaneously a safeguard against members gaming the network. On top, Liquidnet also monitors its members' trade activity. To further customize the anonymity level for their trading requirements, members can completely exclude orders from being considered or they can define a tolerance level for their indication to other members (Liquidnet 2001, p. 4). For the latter, only those trade intensions will be indicated among two members, which exceed the tolerance levels of both.

Another important aspect for institutional investors is trading control. This is established by Liquidnet's decentralized bilateral negotiation approach that avoids committed orders. In contrast, most other dark pool approaches like Crossing Networks are based on a centralized system similar to client-server architecture. Thus, trade intensions which are brought to these systems are committed. Although unexecuted orders can be canceled, traders have no control until the final acknowledgement. Consequently, if they send their orders to some of these systems, they also risk that the desired volume will be executed many times. The nature of an optional venue for executions without market impact is also incentivized by Liquidnet's pricing scheme: No installation or minimum fees are charged before actual executions take place (Liquidnet 2001, p. 6). The commissions to be paid for negotiated trades are said to be 7 bps (Mehta 2007).

To increase the number of executions - the following numbers are based on US equities only - from approximately $14 \%$ to $21.5 \%$ of the latent liquidity provided by its members (SEC 2008), Liquidnet has been recently employing secondary strategies which aim at integrating sell-side liquidity. Nevertheless, as an optional offer to its members, this does not violate its general principle of a closed buy-side user group. 


\section{Study Setup}

\subsection{Dataset Description}

The data for our analyses stems from two sources: The first is the multilateral trading facility (agency broker dark pool) Liquidnet Europe Limited. Beside the instrument, each record includes the execution's date and time stamp with a granularity of one second, as well as its price and currency. Because of Liquidnet's negotiation mechanism, no further information exists of whether an execution has been triggered by a buyer or seller.

Second, for the price benchmark for these trades, we collected order book data from each instrument's home market valid at the reported trade time (benchmark prices). This data originates from Reuters DataScope Tick History and includes quoted limit prices and volume information for both sides of the order book (best bid and ask). Since the available time stamps are based on milliseconds, the latest order book situation is selected which becomes valid just before the second of the reported execution time. Regarding our research approach, the Reuter's data exhibits two limitations that needs been dealt with during the data selection as well as the actual hypothesis test: first, it lacks of secured information indicating volatility interruptions and second it contains no data concerning hidden liquidity.

In a first step, trade reports have been collected for 57 trading days in the period between the $12^{\text {th }}$ of November 2008 and 13 $3^{\text {th }}$ of February 2009. This data consists of 1650 trades. To ensure that only instruments are employed with a primary listing at an exchange featuring a fully-electronic open CLOB, the constituents of the Dow Jones EURO STOXX 50 Index as of November 2008 have been selected. This choice grants the inclusion of the most actively traded instruments in Euro currency. From the EURO STOXX 50 constituents, 39 instruments with 205 actual executions are included in the Liquidnet trade reports. Their primary listings belong to 7 exchanges; namely the three Euronext markets Amsterdam, Brussels and Paris, the Deutsche Börse trading system Xetra (Frankfurt), the Helsinki Stock Exchange's NASDAQ OMX, the Borsa Italiana Milan and the Bolsa de Madrid.

Further, to avoid outliers caused by abrupt price changes at the instruments' primary markets, only executions during continuous trading have been kept: for the case of scheduled auctions start and end times have been extended by a buffer of 2 minutes. Thereby, five Liquidnet records taking place in this time interval have been excluded. As volatility interruptions last at the considered exchanges more than two minutes, all executions have been discarded whose corresponding home market's reference price is older than this amount of time. This affected two additional records yielding to a final data set of 198 Liquidnet executions. As their reference price's validity starts within 17 seconds before the trades, it is ensured that volatility interruptions do not affect the forthcoming results.

Table 1 aggregates the properties of these 198 Liquidnet executions. There, instruments with a primary listing at Euronext Paris are most often included for both 
the traded number of instruments as well as actual executions performed at Liquidnet. Only with a slight difference, the second frequent primary listings originate from Deutsche Börse's Xetra trading system. As expected, the average trade values of the Liquidnet executions are considerably higher than trades qualified as large compared to the Normal Market Size (NMS), i.e. $500.000 €$ (CESR 2008), or compared to the common definition of block trades to exceed 10,000 shares (O'Hara 1997, p. 233). The only exception is Fortis with its primary market Brussels. Although, it's only trade with nearly $700 \mathrm{k} €$ is still large, it is considerably smaller than the other Liquidnet executions exhibiting an average value of about $3.5 \mathrm{~m} €$ per trade.

Table 1: Liquidnet execution characteristics for the analyzed EURO STOXX 50 constituents

\begin{tabular}{lcccccc}
\hline \multirow{2}{*}{$\begin{array}{l}\text { Primary } \\
\text { Listing }\end{array}$} & Instruments & Trades & $\begin{array}{c}\text { Average } \\
\text { per Trade }\end{array}$ & \multicolumn{2}{c}{$\begin{array}{c}\text { Executions } \\
\text { at / within }\end{array}$} \\
\cline { 3 - 7 } Amsterdam & 4 & 17 & 244,026 & $3,505,049$ & $23.53 \%$ & $76.47 \%$ \\
\hline Brussels & 1 & 1 & 500,000 & 696,250 & $0.00 \%$ & $100.00 \%$ \\
\hline Paris & 16 & 89 & 175,215 & $4,123,553$ & $37.03 \%$ & $67.42 \%$ \\
\hline Frankfurt & 12 & 63 & 104,576 & $3,127,026$ & $42.86 \%$ & $77.78 \%$ \\
\hline Helsinki & 1 & 1 & 400,000 & $3,936,000$ & $0.00 \%$ & $100.00 \%$ \\
\hline Milan & 2 & 4 & 450,000 & $3,045,163$ & $50.00 \%$ & $75.00 \%$ \\
\hline Madrid & 3 & 23 & 247,157 & $2,478,724$ & $86.69 \%$ & $86.69 \%$ \\
\hline All & 39 & 198 & 175,331 & $3,522,264$ & $43.43 \%$ & $74.24 \%$ \\
\hline
\end{tabular}

From the descriptive statistics, we can conclude that finding counterparties for a given trade intention appears difficult: during the 57 trading days we have analyzed, 198 trades of EURO STOXX 50 constituents have been observed only. However, since $74.24 \%$ of the Liquidnet executions are being priced inside market (i.e. between the best bid/ask limit prices) and even $43.43 \%$ correspond to the home market's midpoint, Liquidnet executions appear beneficial.

\subsection{Modeling Price Improvement}

In order to assess prices that can be realized when trading within a dark pool, we model the price improvement of these systems in comparison to an alternative different trading venue. The validity of later price benchmark depends on the capability of the chosen market to reflect the instrument's current consensus value. Thus, one has to choose the market offering the most reliable and stable price discovery. Because of the strong network externalities of security markets and the bome market principle for European equities - i.e. the national (home) market of an instrument is 
the most liquid one (Schwartz and Francioni 2004, p. 88) - we have chosen the home market. As benchmark prices we have taken best bid/ask limits ( $p_{B}$ and $p_{A}$ ) as they represent the best prices that can be achieved within the moment of the actual Liquidnet trade. This benchmark represents an optimistic execution as the average of the maximal of best ask/bid limit volumes represents just $6.17 \%$ of the average Liquidnet trade volume.

Based on this information, midpoints and bid-ask spreads (inside market) are calculated, which determine the benchmark for the dark pool executions. Given a sample of dark pool executions and benchmark data, we can model whether or not firms utilizing the dark pool can add value to their trading compared to the benchmark prices (see Figure 2).

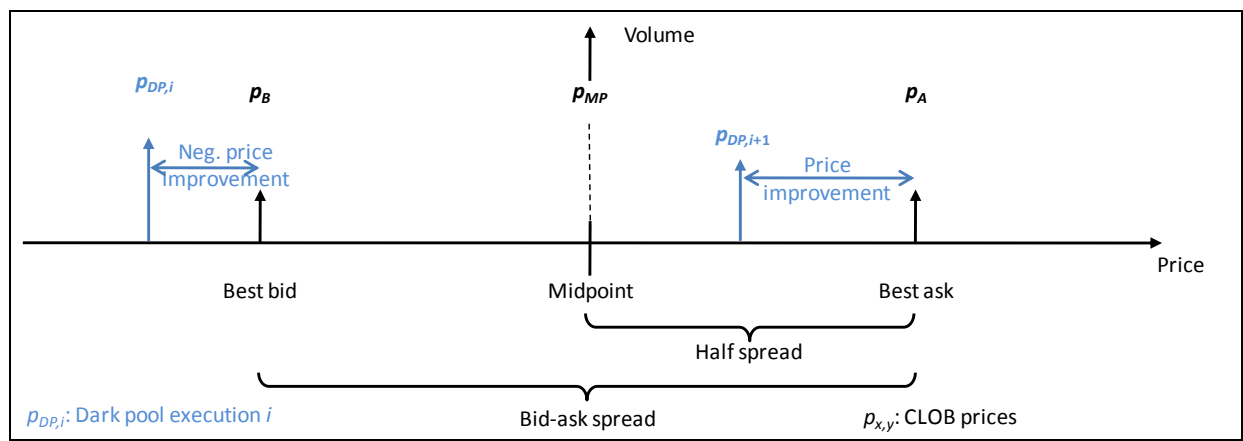

\section{Figure 2: Modeling price improvement}

For a given order book limit, we first calculate a corresponding midpoint. Then, given benchmark prices $\left(p_{A}\right.$ and $\left.p_{B}\right)$, a half spread is calculated for both levels:

$$
\text { half spread }=\frac{p_{A}-p_{B}}{2}
$$

The half spread describes the price difference between the bid/ask-price and the midpoint. For each dark pool execution $i$ and the corresponding execution prices $p_{D P, i}$ a price improvement is calculated. This price improvement is defined as the absolute price difference between dark pool executions and the half spread:

$$
\text { price improvement }_{i}=\mid \text { half spread }|-| p_{D P, i}-p_{\text {Midpoint }} \mid
$$

If the dark pool execution price is inside market, this will result in a positive price improvement or, if not, in a negative price improvement.

\subsection{Research Hypothesis}

We aim at exploring the potential benefits for investors trading via Liquidnet, i.e. to address the question if they can add sustainable more value to their trading by 
achieving better executions (price improvements) compared to benchmark prices, i.e. the best prices achievable at the instrument's primary market. As market microstructure theory suggests, large blocks of shares should trade at "worse" prices (O'Hara 1997, p. 233). If executions observed at Liquidnet are not "worse" but "better" than primary market prices, a significant business value is provided. Using the metrics defined in the previous section, a corresponding hypothesis is formulated in the following.

In order to compare Liquidnet executions with primary market prices, we formulate research hypothesis $H 1$ and a corresponding statistical null hypothesis $H 1_{0}$ :

\section{H1: On average, the price improvement of Liquidnet executions is significantly positive .}

$H 1_{0}: \mu($ price improvement $) \leq 0$

If $H 1_{0}$ can be rejected, there exists statistical evidence that investors having access to Liquidnet can realize significant better execution prices, i.e. they can add sustainable more value to their trading. This will provide evidence whether trading high order volumes at Liquidnet can help investors to avoid market impact (i.e. transaction costs) and consequently to trade in a significantly more profitable way.

\section{Empirical Results}

For each of the 198 observed executions, price improvements have been calculated and collected. Using Reuters DataScope Tick History data which comprise quoted price for the best bid and ask prices, half spreads (benchmark data) and midpoint prices were calculated. Characteristics of the generated analysis samples are provided in Table 2.

Table 2: Descriptive statistics of the analysis samples

\begin{tabular}{lcc}
\hline & \multicolumn{2}{c}{$\begin{array}{c}\text { Liquidnet execution prices vs. } \\
\text { CLOB prices }\end{array}$} \\
\cline { 2 - 3 } & $\left|p_{D P, i}-p_{\text {Midpoint }}\right|$ & half spread \\
\hline Mean & 0.0121 & 0.0137 \\
Median & 0.0025 & 0.0100 \\
St. deviation & 0.0247 & 0.0147 \\
\hline
\end{tabular}

Since we observed outliers in the data due to narrow bid-ask spreads, we applied a non-parametric (Wilcoxon signed-rank) test procedure in addition to a standard parametric (paired $t$-test) test. Given the non-parametric test results in Table 3, it is possible to reject the null hypothesis $H 1_{0}$ at a $1 \%$ level of significance. 
Table 3: Statistical test results

\begin{tabular}{lc}
\hline & $\begin{array}{c}\text { Research } \\
\text { hypothesis } H 1\end{array}$ \\
\cline { 2 - 2 } Test statistic & $\mu($ price improvement $) \leq 0$ \\
\hline Parametric $t$-value & 0.9426 \\
non-parametric $z$-value & $3.9878^{* * * *}$ \\
\hline
\end{tabular}

*** indicates significance at the 1\%level

Regarding the business value provided by Liquidnet there is strong statistical evidence $(H 1)$ that significant higher trading profitability can be realized by members when trading block orders via Liquidnet.

\section{Summary and Conclusion}

This paper addressed the question whether dark pools can successfully address problems of institutional investors with high trading volumes (block orders).

Therefore, trade report data from a major agency broker dark pool (Liquidnet Europe) has been investigated. First, we have analyzed Liquidnet trades in terms of prices and trading volumes. Second, we have introduced a benchmark for Liquidnet trades, based on optimally achievable prices at the instruments' primary markets.

Our major findings were twofold: given the limited number of Liquidnet trades we have observed during the observation period it becomes obvious that finding counterparties within the dark pool is not very likely. However, if a counterparty is found, execution prices are significantly better than the best bid/ask limits of the primary markets. We furthermore have shown that within the dark pool, investors search for trading partners desiring high-volume trades, which would have resulted in significant market impact at markets exhibiting an open order book approach. Since the market mechanism of Liquidnet avoids any market impact for these block trades, the benefits are even more significant for these trading scenarios.

For a detailed quantitative assessment of alternative trading systems such as dark pools, the introduced benchmark approach needs further refinements: therefore, we aim at incorporating reference price corridors including a theoretically derived optimum, an indication for an average trader based on volume weighted average trade prices as well as a worst case scenario. Furthermore, the modeling of execution probabilities is subject to further research. In order to gain deeper insights into the benefits of dark pools, we aim at including further dark pools such as Posit and NYFIX Euromillennium to reveal individual similarities and differences. Another aspect which requires further investigations is the risk of unexecuted trade intensions within dark pools. 


\section{Acknowledgment}

We thankfully acknowledge the support of the E-Finance Lab, Frankfurt for this work.

\section{References}

Battalio R, Greene J, Hatch B, Jennings R (2002) Does the Limit Order Routing Decision Matter?. Review of Financial Studies 15(1):159-194.

Bikker JA, Spierdijk L, van der Sluis PJ (2007) Market Impact Costs of Institutional Equity Trades. Journal of International Money and Finance 26(6):974-1000.

CESR (2008) Shares admitted to trading on EU Regulated Markets.

http:/ / mifiddatabase.cesr.eu/Index.aspx?Sectionlinks_id $=14 \&$ language $=0 \& p a$ geName=MiFIDLiquidSearch. Requested 2009-02-19.

Chan LK, Lakonishok J (1995) The Behavior of Stock Prices Around Institutional Trades. Journal of Finance 50(4):1147-1174.

Domowitz I, Yegerman H (2005) Measuring and Interpreting the Performance of Broker Algorithms (Research Report).

Foucault T, Menkveld AJ (2008) Competition for Order Flow and Smart Order Routing Systems. Journal of Finance 63(1):119-158.

Gsell M, Gomber P (2009) Algorithmic trading engines versus human traders - Do they behave different in securities markets? In: Proceedings of the $17^{\text {th }}$ European Conference on Information Systems, Verona.

Harris L (2003) Trading and Exchanges: Market Microstructure for Practitioners. Oxford, New York.

Henderschott T, Mendelson H (2000) Crossing Networks and Dealer Markets: Competition and Performance, Journal of Finance, 55, pp. 2071-2115.

Kohli R, Devaraj S (2003) Measuring Information Technology Payoff: A MetaAnalysis of Structural Variables in Firm-Level Empirical Research, Information Systems Research 14(2):127-145.

Liquidnet (2001) Liquidnet, An Overview: Business Functionality Report.

Liquidnet (2009) Web Presence, www.liquidnet.com/aboutMembership/Community.html.

Requested 2009-02-20.

Madhavan A (2000) Market Microstructure: A Survey, Journal of Financial Markets 3(3):205-258. 
Mehta N (2007) Europe Overhauled: MiFID Pushes Trading into New Era, Traders Magazine. https://www.tradersmagazine.com/issues/20070910/2909_ 1.html?page $=5$. Requested 2009-02-18.

O'Hara M (1997) Market Microstructure Theory, Blackwell, Malden.

Prix J, Loistl O, Huetl M (2007) Algorithmic Trading Patterns in Xetra Orders. European Journal of Finance 13(8):717-739.

Schwartz R (2009) Crossing Continents, The Trade, http://www.thetrade.ltd.uk/archive_001_Crossing.asp.

Requested 2009-02-22.

Schwartz R, Francioni R (2004) Equity Markets in Action: The Fundamentals of Liquidity, Market Structure \& Trading. Wiley, Hoboken.

Schwartz RA, Steil B (2002) Controlling Institutional Trading Costs. Journal of Portfolio Management 28(3):39-49.

SEC (2008) Primary Listing Prospectus for LIQUIDNET HOLDINGS, INC, https://www.secinfo .com/dVut2.tBS7.htm. Requested 2009-02-19.

Spicer, J (2009) SEC spotlight puts "dark pool" venues on defensive. Reuters, 19th June 2009. http://www.reuters.com/article/ousiv/idUSTRE55I5V020090619. Requested 2009-10-11.

The Economist (2009): The rise of dark pools - Attack of the clones. 2nd July 2009. http://www.economist.com/businessfinance/displaystory.cfm? story_id= 13944858. Requested 2009-09-24. 